\title{
BMJ Open Patient outcomes and costs associated with functional medicine-based care in a shared versus individual setting for patients with chronic conditions: a retrospective cohort study
}

\author{
Michelle Beidelschies (D) , ${ }^{1}$ Marilyn Alejandro-Rodriguez, ${ }^{2}$ Ning Guo, ${ }^{3}$ \\ Anna Postan, ${ }^{4}$ Tawny Jones, ${ }^{1}$ Elizabeth Bradley, ${ }^{1}$ Mark Hyman, ${ }^{1}$ \\ Michael B Rothberg ${ }^{5}$
}

To cite: Beidelschies M, Alejandro-Rodriguez M, Guo N, et al. Patient outcomes and costs associated with functional medicine-based care in a shared versus individual setting for patients with chronic conditions: a retrospective cohort study. BMJ Open 2021;11:e048294. doi:10.1136/ bmjopen-2020-048294

- Prepublication history and supplemental material for this paper is available online. To view these files, please visit the journal online (http://dx.doi org/10.1136/bmjopen-2020048294).

Received 21 December 2020 Revised 19 February 2021 Accepted 08 March 2021
Check for updates

(C) Author(s) (or their employer(s)) 2021. Re-use permitted under CC BY-NC. No commercial re-use. See rights and permissions. Published by BMJ.

For numbered affiliations see end of article.

Correspondence to Dr Michelle Beidelschies; beidelm2@ccf.org

\section{ABSTRACT}

Objective To compare outcomes and costs associated with functional medicine-based care delivered in a shared medical appointment (SMA) to those delivered through individual appointments.

Design A retrospective cohort study was performed to assess outcomes and cost to deliver care to patients in SMAs and compared with Propensity Score (PS)-matched patients in individual appointments.

Setting A single-centre study performed at Cleveland Clinic Center for Functional Medicine.

Participants A total of 9778 patients were assessed for eligibility and 7323 excluded. The sample included 2455 patients (226 SMAs and 2229 individual appointments) aged $\geq 18$ years who participated in in-person SMAs or individual appointments between 1 March 2017 and 31 December 2019. Patients had a baseline PatientReported Outcome Measurement Information System (PROMIS) Global Physical Health (GPH) score and followup score at 3 months. Patients were PS-matched 1:1 with 213 per group based on age, sex, race, marital status, income, weight, body mass index, blood pressure (BP), PROMIS score and functional medicine diagnostic category.

Primary and secondary outcome measures The primary outcome was change in PROMIS GPH at 3 months. Secondary outcomes included change in PROMIS Global Mental Health (GMH), biometrics, and cost.

Results Among 213 PS-matched pairs, patients in SMAs exhibited greater improvements at 3 months in PROMIS GPH T-scores (mean difference 1.18 (95\% Cl 0.14 to 2.22), $\mathrm{p}=0.03$ ) and PROMIS GMH T-scores (mean difference 1.78 (95\% $\mathrm{Cl} 0.66$ to 2.89), $\mathrm{p}=0.002$ ) than patients in individual appointments. SMA patients also experienced greater weight loss $(\mathrm{kg})$ than patients in individual appointments (mean difference $-1.4(95 \% \mathrm{Cl}-2.15$ to -0.64$), \mathrm{p}<0.001)$. Both groups experienced a $5.5 \mathrm{~mm} \mathrm{Hg}$ improvement in systolic BP. SMAs were also less costly to deliver than individual appointments.

Conclusion SMAs deliver functional medicine-based care that improves outcomes more than care delivered in individual appointments and is less costly to deliver.
Strengths and limitations of this study

- This study is the first to describe the delivery of functional medicine-based care in a shared medical appointment (SMA) setting within an academic medical centre and to compare it to individual appointments.

- The results may have broad implications for the management of chronic disease as healthcare continues to navigate the delivery of value-based care.

- This study cannot ascertain the specific aspect of the SMA setting integral to improved outcomes.

- A non-response bias may have artificially inflated observed differences in outcomes.

\section{INTRODUCTION}

Chronic conditions-including obesity, diabetes and cancer-are prevalent and costly burdens to the health systems of Western countries. Approximately $60 \%$ of adults have at least one chronic condition and $42 \%$ have more than one, accounting for $90 \%$ of U.S. annual healthcare expenditures. ${ }^{12}$ Compounding this epidemic is an ageing population with risk factors for chronic disease (eg, tobacco use, poor nutrition and sedentary behaviour), a physician workforce suffering from burnout ${ }^{3}$ and shortages, ${ }^{4}$ and inadequate time to deliver nutrition education $^{5}$ necessary to combat chronic disease. Innovative delivery models are warranted to overcome these challenges.

Shared medical appointments (SMAs) have shown promise for treating chronic conditions. First proposed in 1999, ${ }^{6}$ SMAs employ a multidisciplinary team approach to provide patient-centred care. SMAs have been shown to improve clinical outcomes in various conditions including type 2 diabetes, ${ }^{7-9}$ 
obesity ${ }^{10}{ }^{11}$ chronic cardiac diseases ${ }^{12-14}$ and chronic pain. ${ }^{15-17}$ Several studies found this delivery model to be less costly than individual appointments, provided sufficient patients are enrolled. ${ }^{18-20}$ The success of SMAs has been attributed to various factors including peer-to-peer support, ${ }^{21}$ group size, ${ }^{22}$ patient-provider relationship, ${ }^{21}$ caregiver time $^{21}$ and increased patient engagement. ${ }^{23} 24$ However, SMAs have not been studied as a tool to deliver functional medicine-based care.

Cleveland Clinic adopted the functional medicine model to deliver value-based care, or high-quality care at a lower cost, for chronic disease. Using systems biology, functional medicine providers implement a root cause approach to identify triggers for illness-for example, poor diet, stress, toxins, allergens, infections, the microbiome, and genetics-while optimising factors often addressed by lifestyle medicine such as nutrition, exercise, sleep, relationships and community. ${ }^{25}$ While lifestyle medicine focuses on the prevention and improvement of chronic disease through lifestyle-based strategies, functional medicine employs a personalised diagnosis and management strategy that primarily relies on the use of 'food as medicine'. This strategy is complemented by lifestyle and behavioural interventions to assist patients in stewarding their own health. This care model as delivered through individual appointments was recently associated with improved patient-reported health-related quality of life (HRQoL) compared with a care delivered in a primary care setting. ${ }^{26}$

To improve access and efficiency, a functional medicinebased SMA called Functioning For Life (FFL) was developed. ${ }^{27}$ This 10-week SMA includes five condition-specific cohorts: weight management, autoimmune, digestive disorders, women's health and diabetes. Each cohort leverages a multidisciplinary team to provide conditionspecific education related to nutrition, lifestyle and behavioural health recommendations. Four sessions are co-led by a medical provider $(\mathrm{MD} / \mathrm{DO} / \mathrm{NP} / \mathrm{PA})$ and health coach and six sessions are led by a registered dietitian. Similar to the group visit model proposed by Noffsinger, ${ }^{28}$ the medical provider and health coach sessions begin with the provider delivering conditionspecific education followed by a limited medical evaluation with each patient in an individual setting. This is achieved by briefly rounding each patient out of the shared setting while a health coach delivers education on lifestyle and behaviour health change and fosters group discussion. The dietitian sessions focus on food as medicine, and support patients in the implementation of an anti-inflammatory, low glycaemic index food plan that encourages consumption of whole, unprocessed foods. While the food plan is offered to everyone, individualisation is common and patients tailor it with clinical oversight. The plan removes foods associated with inflammation (eg, sugar, gluten and dairy) and supports natural detoxification. ${ }^{29}$ Providers may recommend conditionspecific dietary supplementation as an adjunct to the food plan. By the end, patients are empowered to make positive decisions regarding food and become advocates for healthy lifestyles within their homes and communities.

The objective of the current study is to compare HRQoL, biometric outcomes and costs associated with functional medicine-based care delivered in an SMA to similar care delivered through individual appointments.

\section{METHODS}

\section{Study design and populations}

A single-centre, retrospective cohort study was conducted to evaluate the association of HRQoL with patients seen in an FFL SMA programme (hereafter, SMA) versus functional medicine individual appointments (hereafter, individual appointments). Figure 1 summarises the study design. Patients were eligible if $\geq 18$ years old and seen at Cleveland Clinic Center for Functional Medicine from 1 March 2017 to 31 December 2019 in the SMA (weight management, autoimmune, digestive disorders, women's health or diabetes) or individual appointment (SMA: 758; individual appointments: 8972; missing group information: 48). Patients had to have a baseline PROMIS GPH score and a follow-up score at 3 months (90 \pm 30 days). The study followed the Strengthening the Reporting of Observational Studies in Epidemiology (STROBE) guidelines for cohort studies. ${ }^{30}$

The implementation of the SMA and individual appointment is outlined in online supplemental eTable 1. Patients may enter an SMA in several ways. Patients can self-select into an SMA after visiting the centre's webpage or speaking with a scheduling representative. Patients on the centre's waitlist are offered an SMA to expedite access to care and providers may also refer into the programme. In an individual appointment, new patients see a provider $(\mathrm{MD} / \mathrm{DO} / \mathrm{NP} / \mathrm{PA})$, registered dietitian and health coach for a combined total of 4 hours. ${ }^{26}$ Afterwards, patients can schedule follow-up appointments with any caregiver; however, follow-up may be limited by access or patient preference. In the SMA, patients enroll into a cohort with eligibility confirmed by the centre. Frequent follow-up visits are inherent to the SMA. Regardless of visit type (SMA or individual appointment), patients are asked to complete PROMIS at each provider visit within the centre either prior to their visit using a secure patient portal or at the front desk on check-in.

\section{Data}

The Knowledge Program Data Registry, ${ }^{31}$ the IRBapproved Center for Functional Medicine Patient Registry, and LivingMatrix (a cloud-based patient information management system) provided the data for this study. Patient demographics and comorbidities were obtained from patients' electronic health record. Household income was estimated using the median income by Census block, based on the patient's address. HRQoL was measured using PROMIS Scale v1.2 Global Health (PROMIS GH) ${ }^{32}$ as previously reported. ${ }^{26}$ PROMIS GH is scored into PROMIS GPH and GMH summary scores 


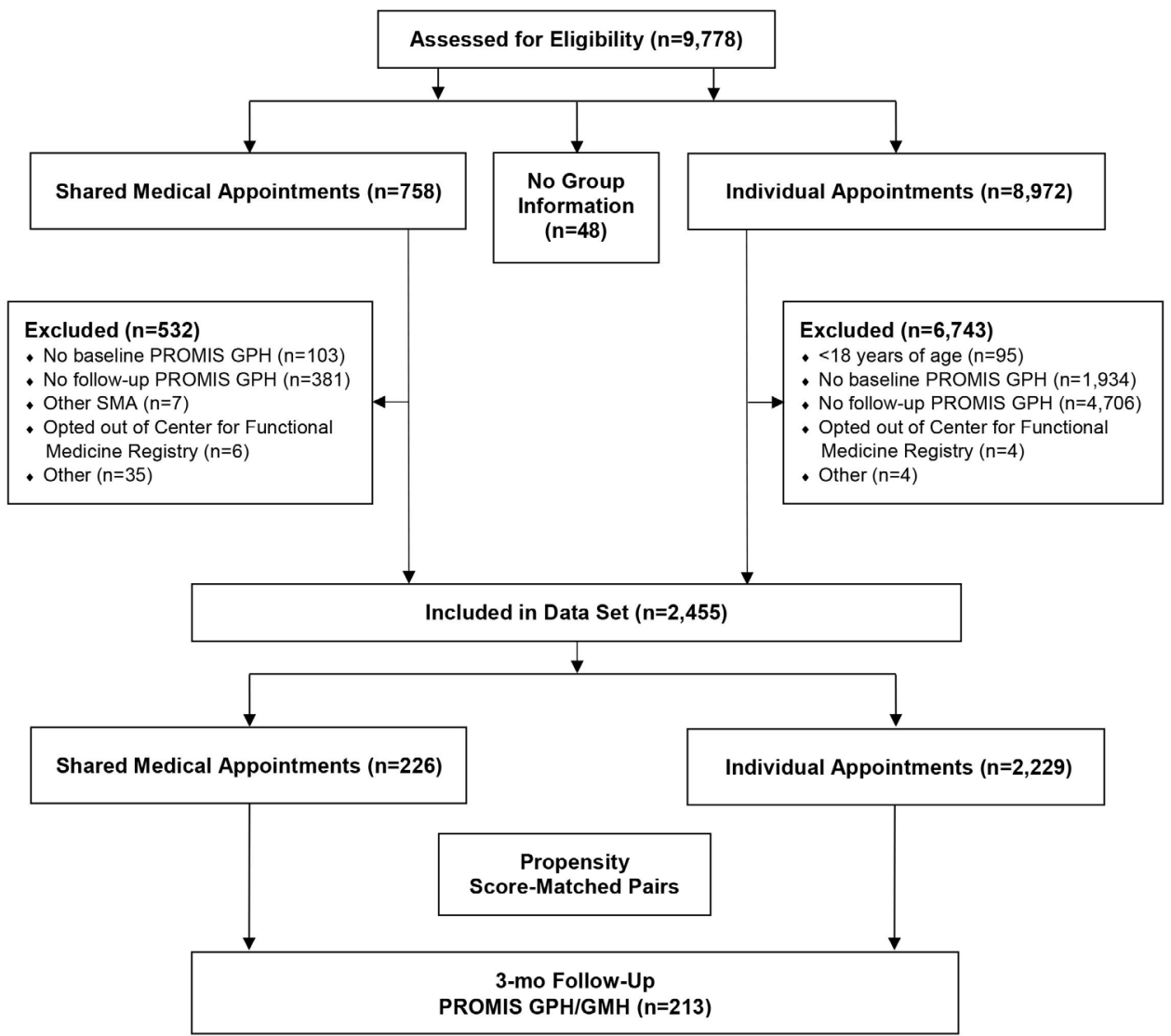

Figure 1 Study flow diagram. GMH, Global Mental Health; GPH, Global Physical Health; PROMIS, Patient-Reported Outcome Measurement Information System.

which are reported herein. Summary scores are centred on the 2000 US Census with respect to age, sex, education, and race/ethnicity and transformed to a T-score with a mean of 50 and SD of $10 .^{32}$ Changes of 5 points or more suggest a minimal clinically important difference. ${ }^{33}{ }^{34}$ PROMIS GPH and GMH scores were examined at baseline (initial visit) and 3 months (follow-up visit).

Because patient engagement at baseline could confound the relationship between delivery mode and outcome, we measured readiness to change for each group using a 10-item survey. Willingness to change (seven questions), confidence (one question), household support (one question) and clinical practice support (one question) were assessed. All items included a 5-point Likert scale, which were summed to yield a composite score ranging from 10 to 50 .

\section{Outcomes}

The primary outcome was change in PROMIS GPH scores from baseline to 3 months. Secondary outcomes included change in PROMIS GMH scores from baseline to 3 months, change in biometrics and cost to deliver care. The cost analysis was conducted from the health system perspective to determine the net revenue (margin) received from delivering each care model. Patients' insurances were billed for each visit attended. Estimated revenue for the cohort was calculated by applying a generic realisation rate to actual billed charges. Cost of providing either the SMA or individual appointment was calculated based on the expense (salary, wages and benefits) for caregiver time for all functional medicine visits over 3 months. Margin represents the difference between revenue and cost.

\section{Statistical analysis}

Descriptive statistics are reported for all patients. Baseline demographics, biometrics (weight, body mass index (BMI) and blood pressure), functional medicine diagnostic category, baseline PROMIS GH, attendance within the SMA and total number of visits within 3 months were summarised using frequency count with percentage for categorical variables and mean with $\mathrm{SD}$, or median with IQR, for continuous variables, as appropriate. Characteristics were compared across groups using $\mathrm{X}^{2}$ test for categorical variables and t-test, or Mann-Whitney $\mathrm{U}$ test, as appropriate, for continuous variables. Characteristics were compared for included and excluded patients (online supplemental eTable 2). Diagnostic categories were organised based on International Classification of Disease (ICD)-10 diagnoses. ${ }^{26}$

Propensity score (PS) matching was used to compare changes in HRQoL and biometric outcomes between SMAs and individual appointments. PSs were estimated with multivariable logistic regression including the following baseline variables: age, sex, race, marital status, income, weight, BMI, blood pressure, PROMIS GPH and 
GMH scores, and functional medicine diagnostic category. A 1:1 match was performed with non-replacement and a calliper of 0.2. Baseline characteristics and outcomes were compared between groups before and after PS matching using standardised differences, with differences less than $20 \%$ considered acceptable. ${ }^{35}$ Since all characteristics were balanced, no further adjustments were made when comparing outcomes.

A subanalysis was performed on the PS-matched groups using a 10-item baseline readiness to change survey. Total composite scores were compared between groups using the Mann-Whitney U test.

Continuous outcomes were compared using paired t-test within groups and unpaired t-test between groups. A 95\% CI for the mean change was calculated. The proportion of patients who improved GPH or GMH by five points or more was examined using McNemar's test, and based on the difference in proportions, the number needed to treat (NNT) was calculated.

Statistical analyses were conducted using SAS V.9.4 (SAS Institute). Statistical significance was established at $\mathrm{p}<0.05$.

\section{Patient and public involvement}

Patients and the public were not involved in any aspect of this study or in the writing or editing of this manuscript.

\section{RESULTS}

In total, 2455 new patients from the Center for Functional Medicine (SMAs: 226 and individual appointments: 2229) were included (figure 1). Mean (SD) age of all patients was 48.5 (14.5), $81.0 \%$ were female and $91.1 \%$ were non-Hispanic white. The majority of SMA patients participated in the weight management $(36 \%)$ and autoimmune $(34 \%)$ programme cohorts. Table 1 reviews the cohort characteristics prior to propensity matching. SMA patients had higher baseline PROMIS GPH and GMH scores, higher baseline weight and blood pressure, and were more likely to have a diagnosis related to one of the cohorts. SMA patients had a higher mean (SD) number of visits within 3 months than those in individual appointments $(9.1$ (2.0) vs $2.2(1.1), \mathrm{p}<0.001)$. Of the total population, 125 of $2455(5.1 \%)$ observations were omitted due to missing baseline data on biometrics, PROMIS GMH or household income. After successful 1:1 PS matching, there were 213 patients in each group and no differences in baseline characteristics (table 2). Importantly, there were no differences in median $(\mathrm{Q} 1, \mathrm{Q} 3)$ baseline total composite patient readiness to change scores between the two groups (SMA: $45.0(42.0,47.0)$ vs Individual: 45.0 $(43.0,48.0), \mathrm{p}=0.07)$. The distribution of PS-matched patients within the SMA cohorts was as follows: autoimmune $(35 \%)$, weight management $(34 \%)$, digestive disorders $(17 \%)$, women's health $(8 \%)$ and diabetes $(5 \%)$. SMA visits were well attended (online supplemental eTable 3) with $86 \%$ of patients participating in seven or more visits (online supplemental eTable 4).
Table 3 reports the changes in mean (SD) PROMIS GH. At 3 months, SMA patients had a significantly greater improvement in PROMIS GPH T-scores than was seen with individual appointments (3.30 (5.66) vs 2.12 (5.28); mean difference 1.18 ( $95 \%$ CI 0.14 to 2.22 ), $\mathrm{p}=0.03$ ). SMA patients were also more likely to experience improvements of 5 or more points $(38 \%$ vs $28 \%$, NNT $=10)$, but the differences were not significant $(\mathrm{p}=0.09)$.

SMA patients had a significantly greater improvement in PROMIS GMH T-scores than was seen with individual appointments (3.12 (6.28) vs 1.34 (5.36); mean difference 1.78 (95\% CI 0.66 to 2.89), $\mathrm{p}=0.002$ ). SMA patients were also more likely to experience improvements of 5 or more points ( $38 \%$ vs $26 \%, \mathrm{NNT}=8)$, but the differences were not significant $(\mathrm{p}=0.07)$.

Table 4 demonstrates the mean (SD) biometric changes in the PS-matched groups. At 3 months, SMA patients had a significantly greater improvement in their weight than was seen with individual appointments $(-3.8$ (4.1) vs -2.4 (3.6) $\mathrm{kg}$; mean difference -1.4 (95\% CI -2.15 to $-0.64), \mathrm{p}<0.001)$. This equated to a mean weight loss of $4.4 \%$ in the SMA and $2.8 \%$ in individual appointments. Compared with baseline, both groups experienced similar improvements in their systolic (SMA: -5.5 (15.7) vs Individual: -5.5 (15.2) $\mathrm{mm} \mathrm{Hg}$; mean difference -0.03 (95\% CI -3.06 to 2.99 ), $\mathrm{p}=0.98$ ) and diastolic (SMA: -2.9 (10.8) vs individual: -4.1 (10.9) $\mathrm{mm} \mathrm{Hg}$; mean difference $1.2(95 \%$ CI -0.96 to 3.30$), \mathrm{p}=0.28)$ blood pressures.

The cost analysis appears in online supplemental eTable 5. In the PS-matched population, the average number of visits over 3 months was approximately 9.0 in the SMA and 2.0 in the individual appointment setting (online supplemental eTable 6). Average enrolment within the SMA was 6.0 patients. SMA patients received more caregiver time per patient than those in individual appointments ( 14.0 hours vs 3.5 hours), but the SMA cost less to deliver (US $\$ 1549$ vs US $\$ 1633$ per patient) and generated greater revenue (US $\$ 4204$ vs US $\$ 3780$ per patient). Per patient cost associated with the delivery of the SMA were fixed at US $\$ 1549$ and breakeven was achieved when at least three patients were enrolled in a cohort (online supplemental eFigure 1). Profitability of the SMA exceeded that of individual appointments when at least six patients were enrolled (online supplemental eFigure 2).

\section{DISCUSSION}

SMAs offer a promising solution to efficiently mitigate the impact of chronic disease. ${ }^{36}$ To our knowledge, this is the first study to describe the delivery of functional medicinebased care in an SMA setting within an academic medical centre, the first to compare it to individual appointments, and the first to examine the economics of providing such care. A recent study of individual appointments in a functional medicine setting demonstrated that this care model is associated with significant improvements in PROMIS GPH and GMH. ${ }^{26}$ The current study extends those findings and reports significant improvements 
Table 1 Cohort characteristics by appointment type, $n=2445$

\begin{tabular}{|c|c|c|c|}
\hline Characteristic & Shared medical appointments N (\%) & Individual appointments N (\%) & $P$ value \\
\hline Patients, No. & 226 & 2229 & \\
\hline Age, mean (SD), year & $49.5(12.8)$ & $48.4(14.6)$ & 0.26 \\
\hline Women & $190(84.1)$ & $1799(80.7)$ & 0.22 \\
\hline Caucasian & $198(87.6)$ & 2039 (91.5) & 0.052 \\
\hline Married & $150(66.4)$ & $1524(68.4)$ & 0.54 \\
\hline Household income, ${ }^{\star}$ median, IQR & $59553(27700)$ & $60979(27814)$ & 0.17 \\
\hline \multicolumn{4}{|l|}{ Programme attendance } \\
\hline Weight management & $81(35.8)$ & NA & NA \\
\hline Autoimmune & $77(34.1)$ & NA & NA \\
\hline Digestive disorders & $38(16.8)$ & NA & NA \\
\hline Women's health & $18(8.0)$ & NA & NA \\
\hline Diabetes & $12(5.3)$ & NA & NA \\
\hline \multicolumn{4}{|l|}{ Baseline score, mean (SD) } \\
\hline PROMIS GPH & $45.95(7.36)$ & $44.25(8.08)$ & 0.002 \\
\hline PROMIS GMH & $45.98(8.99)$ & $43.63(8.52)$ & $<0.001$ \\
\hline \multicolumn{4}{|l|}{ Baseline biometrics, mean (SD) } \\
\hline Weight $(\mathrm{kg})^{\star}$ & $85.8(24.4)$ & $75.8(20.0)$ & $<0.001$ \\
\hline $\mathrm{BMI}^{*}$ & $30.4(7.8)$ & $27.1(6.6)$ & $<0.001$ \\
\hline Systolic BP* & $131.6(17.9)$ & $124.9(16.6)$ & $<0.001$ \\
\hline Diastolic BP* & $74.7(11.1)$ & $72.8(10.7)$ & 0.014 \\
\hline \multicolumn{4}{|l|}{ Functional medicine diagnostic category $\dagger$} \\
\hline Infections, No. (\%) & $6(2.7)$ & $102(4.6)$ & 0.18 \\
\hline Autoimmune, No. (\%) & $56(24.8)$ & $362(16.2)$ & 0.001 \\
\hline Allergen, No. (\%) & $1(0.44)$ & $71(3.2)$ & 0.020 \\
\hline Cancer, No. (\%) & $3(1.3)$ & $96(4.3)$ & 0.030 \\
\hline Hormones, No. (\%) & $152(67.3)$ & $784(35.2)$ & $<0.001$ \\
\hline Energy, №. (\%) & $74(32.7)$ & $691(31.0)$ & 0.59 \\
\hline Nutrition, No. (\%) & $2(0.88)$ & $10(0.45)$ & 0.37 \\
\hline Mood, No. (\%) & $27(11.9)$ & $416(18.7)$ & 0.012 \\
\hline Neuro, No. (\%) & $36(15.9)$ & 409 (18.3) & 0.37 \\
\hline HEENT, No. (\%) & $0(0.0)$ & $39(1.7)$ & 0.045 \\
\hline CVD, No. (\%) & $40(17.7)$ & $221(9.9)$ & $<0.001$ \\
\hline Gut, No. (\%) & $83(36.7)$ & $566(25.4)$ & $<0.001$ \\
\hline Skin, No. (\%) & $23(10.2)$ & $189(8.5)$ & 0.39 \\
\hline Structure, No. (\%) & $42(18.6)$ & $411(18.4)$ & 0.96 \\
\hline GU, No. (\%) & $32(14.2)$ & $210(9.4)$ & 0.023 \\
\hline Trauma, No. (\%) & $7(3.1)$ & $183(8.2)$ & 0.006 \\
\hline Total visits within 3 months, Mean (SD) $\ddagger$ & $9.1(2.0)$ & $2.2(1.1)$ & $<0.001$ \\
\hline
\end{tabular}

${ }^{*}$ Data not available for all subjects. Missing values: household income $=15, \mathrm{PROMIS} \mathrm{GMH}=3$, systolic $\mathrm{BP}=76$, diastolic $\mathrm{BP}=76$, weight $(\mathrm{kg})=93$, $\mathrm{BMl}=103$.

$\dagger$ Definitions for each category have been provided previously. ${ }^{26}$

$\ddagger$ Total visits is the number of visits within 3 months.

BMI, body mass index; BP, blood pressure; CVD, cardiovascular disease; GMH, Global Mental Health; GPH, Global Physical Health; GU, genitourinary; HEENT, head, eyes, ears, nose, and throat; PROMIS, Patient-Reported Outcome Measurement Information System.

in each measure as well as biometric outcomes for the SMA beyond those achieved in individual appointments. Moreover, nearly $40 \%$ of patients participating in SMAs achieved a minimal clinically important difference compared with $30 \%$ in individual appointments.
Few studies have examined the impact of SMAs on PROMIS GH measures. A comprehensive lifestyle intervention programme delivered in an SMA setting to breast cancer survivors reported a small, non-significant change in PROMIS GPH and no change in PROMIS GMH. ${ }^{37}$ The 
Table 2 Characteristics of propensity score-matched patients with PROMIS GPH scores at 3 months

\begin{tabular}{|c|c|c|c|}
\hline Characteristic & $\begin{array}{l}\text { Shared medical } \\
\text { appointments N (\%) }\end{array}$ & $\begin{array}{l}\text { Individual } \\
\text { appointments N (\%) }\end{array}$ & $\begin{array}{l}\text { Standardised } \\
\text { difference* }\end{array}$ \\
\hline Patients, No. & 213 & 213 & \\
\hline Age, Mean (SD), year & $49.3(12.7)$ & $49.7(14.5)$ & -0.03161 \\
\hline Women & $180(84.5)$ & $179(84.0)$ & 0.01244 \\
\hline Caucasian & $187(87.8)$ & $192(90.1)$ & -0.07576 \\
\hline Married & $140(65.7)$ & $151(70.9)$ & -0.10990 \\
\hline Household income, median, IQR & $59585(26545)$ & 60996 (27 356) & -0.12272 \\
\hline \multicolumn{4}{|l|}{ Baseline score, mean (SD) } \\
\hline PROMIS GPH & $45.76(7.34)$ & $45.25(8.14)$ & 0.06697 \\
\hline PROMIS GMH & $45.77(8.96)$ & $46.17(7.84)$ & -0.04586 \\
\hline \multicolumn{4}{|l|}{ Baseline biometrics, mean (SD) } \\
\hline Weight (kg) & $85.5(24.5)$ & $83.9(23.4)$ & 0.07271 \\
\hline BMI & $30.3(7.8)$ & $29.6(7.4)$ & 0.09238 \\
\hline Systolic BP & $131.4(18.0)$ & $132.4(18.2)$ & -0.05862 \\
\hline Diastolic BP & $74.7(11.3)$ & $75.1(10.3)$ & -0.03645 \\
\hline \multicolumn{4}{|c|}{ Functional medicine diagnostic category $†$} \\
\hline Infections, No. (\%) & $6(2.8)$ & $6(2.8)$ & 0.00000 \\
\hline Autoimmune, No. (\%) & $50(23.5)$ & $56(26.3)$ & -0.07013 \\
\hline Allergen, No. (\%) & $1(0.47)$ & $1(0.47)$ & 0.00000 \\
\hline Cancer, No. (\%) & $3(1.4)$ & $4(1.7)$ & 0.05624 \\
\hline Hormones, No. (\%) & $140(65.7)$ & $141(66.2)$ & -0.00987 \\
\hline Energy, No. (\%) & 70 (32.9) & 71 (32.9) & -0.01006 \\
\hline Nutrition, No. (\%) & $2(0.94)$ & $1(0.47)$ & 0.05642 \\
\hline Mood, No. (\%) & $25(11.7)$ & $25(11.7)$ & 0.00000 \\
\hline Neuro, No. (\%) & 35 (16.4) & $37(17.4)$ & -0.02495 \\
\hline HEENT, No. (\%) & $0(0.0)$ & $0(0.0)$ & 0.00000 \\
\hline CVD, No. (\%) & $36(16.9)$ & $33(15.5)$ & 0.04174 \\
\hline Gut, No. (\%) & $74(34.7)$ & 75 (35.2) & -0.01025 \\
\hline Skin, No. (\%) & $23(10.8)$ & $22(10.3)$ & 0.01597 \\
\hline Structure, No. (\%) & 39 (18.3) & $42(19.7)$ & -0.03664 \\
\hline GU, No. (\%) & $28(13.1)$ & $28(13.1)$ & 0.00000 \\
\hline Trauma, No. (\%) & $7(3.3)$ & $6(2.8)$ & 0.02035 \\
\hline
\end{tabular}

${ }^{*}$ Difference in means or proportions divided by SE. Imbalance defined as absolute value greater than 0.20.

†Definitions for each category have been provided previously. ${ }^{26}$

BMI, body mass index; BP, blood pressure; CVD, cardiovascular disease; GMH, Global Mental Health; GPH, Global Physical Health; GU, genitourinary; HEENT, head, eyes, ears, nose, and throat; PROMIS, Patient-Reported Outcome Measurement Information System.

lack of benefit may have been due to the programme structure (eg, duration, patient population, intervention) or the small study size. ${ }^{33}$

Our weight loss findings are consistent with previous studies over a similar timeframe. Studies of SMAs for pre-diabetes and weight management have found that patients in SMAs lost at least twice as much weight as those with individual visits. Cole et al reported patients participating in a pre-diabetes nutrition SMA lost 3.5\% of their body weight at 3 months compared with $1.8 \%$ in an individual setting. ${ }^{38}$ Recently, Shibuya et al reported mean weight loss of $4.2 \%$ at 6 months for those participating in an obesity-specific SMA compared with $1.5 \%$ in an individual setting. ${ }^{11}$ Whether such weight loss is sustained is an important question for future studies.

Importantly, the SMA was more efficient to deliver than individual appointments-that is, it was able to achieve the desired outcome at lower cost. Efficiency was related to the number of patients per cohort as the cost to deliver the SMA was fixed. Others have linked efficiency to the number of patients per cohort and attendance rates. ${ }^{102}$ Efficiency may also stem from the use of non-physician 
Table 3 Changes in PROMIS GPH and GMH T-scores over time by propensity score-matched group

\begin{tabular}{|c|c|c|c|c|c|}
\hline \multirow[b]{2}{*}{ Outcome } & \multicolumn{2}{|l|}{ Mean (SD) } & \multirow[b]{2}{*}{$\begin{array}{l}\text { Difference in } \\
\text { difference (SE) }\end{array}$} & \multirow[b]{2}{*}{$\begin{array}{l}\text { Difference } \\
\text { in difference } \\
95 \% \mathrm{Cl}\end{array}$} & \multirow[b]{2}{*}{$P$ value } \\
\hline & $\begin{array}{l}\text { Shared medical } \\
\text { appointments } \\
\text { (SMA) }\end{array}$ & $\begin{array}{l}\text { Individual } \\
\text { appointments }\end{array}$ & & & \\
\hline \multicolumn{6}{|l|}{ PROMIS GPH } \\
\hline Baseline to $3 \mathrm{mo}$, No. & 213 & 213 & & & \\
\hline \multicolumn{6}{|l|}{ T-score } \\
\hline $3 \mathrm{mo}$. & $49.07(7.10)$ & $47.37(8.28)$ & & & \\
\hline Change & $3.30(5.66)^{\star} \dagger$ & $2.12(5.28) \dagger$ & $1.18(0.53)$ & $(0.14,2.22)$ & $0.027 \ddagger$ \\
\hline Categorical change (T-Score points) & & & & & $0.088 \ddagger$ \\
\hline Improve $\geq 5.00$, No. (\%) & $80(37.6)$ & $60(28.2)$ & & & \\
\hline Worsen $\geq 5.00$, No. (\%) & $14(6.6)$ & $15(7.0)$ & & & \\
\hline \multicolumn{6}{|l|}{ PROMIS GMH } \\
\hline Baseline to 3 mo, No. & 213 & 213 & & & \\
\hline \multicolumn{6}{|l|}{ T-score } \\
\hline Baseline & $45.77(8.96)$ & $46.17(7.84)$ & & & \\
\hline $3 \mathrm{mo} . \S$ & $48.89(8.39)$ & $47.50(8.38)$ & & & \\
\hline Change§ & $3.12(6.28) \dagger$ & $1.34(5.36) \dagger$ & $1.78(0.57)$ & $(0.66,2.89)$ & $0.002 \ddagger$ \\
\hline Categorical change (T-Score points) $\ddagger$ & & & & & $0.065 \ddagger$ \\
\hline Improve $\geq 5.00$, No. (\%) & $81(38.0)$ & $54(25.5)$ & & & \\
\hline
\end{tabular}

3 months: SMA PROMIS GPH change (95\% CI 2.54 to 4.07$)$; individual appointment PROMIS GPH change (95\% Cl 1.41 to 2.84$)$; SMA PROMIS GMH change ( $95 \% \mathrm{Cl} 2.27$ to 3.97); individual appointment PROMIS GMH change (95\% $\mathrm{Cl} 0.62$ to 2.07).

*Primary outcome.

†Statistically significant improvement within group, $\mathrm{p}<0.05$.

\#For comparison between groups.

§Data not available for all subjects. Missing 3-month values: GMH T-Score=1, GMH T-Score Change=1, and GMH Categorical Change=1. GMH, Global Mental Health; GPH, Global Physical Health; PROMIS, Patient-Reported Outcome Measurement Information System.

caregivers such as physician assistants, nurse practitioners and pharmacists to deliver much of the educational material. Non-physician caregivers in an SMA setting cost less to deploy, can deliver the same quality of care, ${ }^{10} 18$ 39-41 and may alleviate physician shortages. ${ }^{4}$ The multidisciplinary team of caregivers in the current study does not appear to have negatively impacted outcomes.

Patients with higher PROMIS GPH have lower rates of subsequent hospitalisation. ${ }^{42}$ However, it remains to be seen if the current SMA might also reduce future hospitalisation and subsequent healthcare expenditures.

Several factors may have contributed to improved outcomes with SMAs. First, the SMA focused heavily on food as medicine. Nutrition recommendations are notoriously difficult to implement and non-adherence is common. ${ }^{43}$ In individual appointments, patients are introduced to the concept of food as medicine and a food plan. However, patients may choose to not implement it, have difficulty with implementation or fail to follow-up with a dietitian. Recognising these limitations, the SMA dedicated the majority of its visits to nutrition education, provided patients with educational tools and fostered open discussions involving feedback, all of which are known to improve patient adherence. ${ }^{43}$ In this setting, patients learn from each other's illnesses and gain perspective about their health. ${ }^{21}$ With more touchpoints, patients are longitudinally supported through challenging nutritional and lifestyle changes.

Second, the SMA structure offers longitudinal access to a multidisciplinary team of caregivers and consistent 
Table 4 Changes in patient biometrics by propensity score-matched group

\begin{tabular}{|c|c|c|c|c|c|}
\hline \multirow[b]{2}{*}{ Outcome } & \multicolumn{2}{|l|}{ Mean (SD) } & \multirow{3}{*}{$\begin{array}{l}\text { Difference in } \\
\text { difference (SE) }\end{array}$} & \multirow{3}{*}{$\begin{array}{l}\text { Difference in } \\
\text { difference } 95 \% \mathrm{Cl}\end{array}$} & \multirow[b]{3}{*}{$P$ value } \\
\hline & $\begin{array}{l}\text { Shared medical } \\
\text { appointments } \\
\text { (SMAs) }\end{array}$ & $\begin{array}{l}\text { Individual } \\
\text { appointments }\end{array}$ & & & \\
\hline Baseline to 3 mo, No. & 213 & 213 & & & \\
\hline \multicolumn{6}{|l|}{ Weight, kg } \\
\hline Change* $^{*}$ & $-3.8(4.1) \dagger$ & $-2.4(3.6) \dagger$ & $-1.4(0.4)$ & $(-2.15$ to to 0.64$)$ & $<0.001 \ddagger$ \\
\hline \multicolumn{6}{|l|}{ Systolic BP, mm Hg } \\
\hline Baseline & $131.4(18.0)$ & $132.4(18.2)$ & & & \\
\hline 3 mo.* & $125.8(16.8)$ & $127.4(15.8)$ & & & \\
\hline 3 mo.* & $71.9(10.8)$ & $71.2(10.2)$ & & & \\
\hline Change* & $-2.9(10.8) \dagger$ & $-4.1(10.9) \dagger$ & $1.2(1.1)$ & $(-0.96$ to 3.30$)$ & $0.28 \ddagger$ \\
\hline
\end{tabular}

3 Months: SMA weight change $(95 \% \mathrm{Cl}-4.33$ to -3.21$)$; individual appointment weight change (95\% $\mathrm{Cl}-2.89$ to -1.87$)$; SMA systolic $\mathrm{BP}$ change $(95 \% \mathrm{Cl}-7.70$ to -3.39$)$; individual appointment systolic $\mathrm{BP}$ change $(95 \% \mathrm{Cl}-7.64$ to -3.37$)$; SMA diastolic $\mathrm{BP}$ change $(95 \% \mathrm{Cl}-4.43$ to -1.45$)$; individual appointment diastolic BP change (95\% Cl -5.65 to -2.58$)$.

*Data not available for all subjects. Missing 3-month values: systolic blood pressure $=24$, change in systolic blood pressure $=24$, diastolic blood pressure $=24$, change in blood pressure $=24$, weight $=24$, change in weight $=24$.

†Statistically significant improvement within group, $p<0.05$.

‡For comparison between groups.

$\mathrm{BP}$, blood pressure.

delivery of functional medicine-based care. Regular follow-up visits are inherent to the SMA structure and circumvent scheduling issues patients may face in an individual appointment setting. Although the programme was comprised of 10 visits, attendance rates exceeded those reported for similar conditions delivered within SMAs. ${ }^{1021}$ Moreover, the SMA delivers a consistent, protocol-based approach to functional medicine as opposed to the individual appointment setting where physician variation may affect care. The SMA efficiently delivers care to the group, allowing the provider to invest more time in group discussion, learn how to meet patient needs and build therapeutic relationships.

Lastly, the SMA focuses on health literacy. Limited health literacy is recognised as a contributor to poor selfmanagement ${ }^{44}$ and declining physical function status ${ }^{45}$ in those with chronic conditions. The ability to improve health literacy in an individual appointment may be challenging due to available time and patient goals for the appointment. However, the SMA operational structure allows for ample time to deliver educational content through didactics, encourage open group discussion and review educational handouts. Education is delivered in a coordinated fashion that aligns with an educational portal housing various resources (eg, recipes, shopping guides, exercise routines, etc). The SMA is an active learning environment where patients are encouraged to ask questions, set personal goals and become aware of how their bodies could function better if provided with optimal nutrition, adequate hydration, moderate exercise and optimal sleep. An active learning environment such as this may improve health literacy ${ }^{46}$ support behaviour change and contribute to sustained improvements in physical health. ${ }^{47}$

The study has several limitations. First, a large number of patients with no baseline or follow-up PROMIS were excluded from eligibility. These patients were more likely to be within the individual appointment group as the SMA setting is newer to the centre and represents a smaller percentage of the total population assessed for eligibility. Regardless, suboptimal patient participation in PROMIS may exist for both groups and be due to several factors including a lack of MyChart use, partial survey completion, administration oversight of survey distribution during the check-in process, lack of perceived utility of the survey on behalf of the patient, or lack of patient follow-up within the windows defined within the current study. Second, there may have been a selection bias in which patients who chose to enter the SMA were more motivated than comparison patients. We tried to avoid this through propensity matching. Moreover, we compared patient activation based on our baseline readiness to change surveys and found it was similar between the two groups, suggesting that selection bias was not an 
important contributor. However, we are unable to account for the readiness to change for those excluded from the study. Therefore, our results cannot be generalised to less motivated individuals. Third, PS matching resulted in the loss of a small percentage of the already limited SMA patient population. However, this step was necessary due to the differences in baseline PROMIS GH scores and biometrics between patients in the SMA and individual appointment groups. Therefore, generalisations regarding PS-matched patients within each group to all patients within their respective groups should be avoided. Lastly, a non-response bias may exist as those who are lost to follow-up may not have received the same benefit as those who completed the SMA, artificially inflating the observed differences.

Future studies should examine longitudinal outcomes of the SMA for both in-person and virtual programmes as well as its ability to reduce healthcare utilisation (eg, medication use, hospitalisation, etc).

\section{Conclusion}

The current study demonstrates that a functional medicine-based SMA is associated with improved HRQoL and biometric outcomes and costs less to deliver than individual appointments. This innovative care delivery model may be a solution for healthcare organisations and medical practices who care for chronic disease populations where a food as medicine approach may be beneficial.

\section{Author affiliations \\ ${ }^{1}$ Center for Functional Medicine, Cleveland Clinic, Cleveland, Ohio, USA \\ ${ }^{2}$ Community Health and Partnerships, Cleveland Clinic, Cleveland, Ohio, USA \\ ${ }^{3}$ Quantitative Health Sciences, Cleveland Clinic, Cleveland, Ohio, USA \\ ${ }^{4}$ Community Care, Cleveland Clinic, Cleveland, Ohio, USA \\ ${ }^{5}$ Internal Medicine, Cleveland Clinic, Cleveland, Ohio, USA}

Acknowledgements The authors would like to thank all past and present caregivers at the Center for Functional Medicine involved in the delivery of the Functioning For Life shared medical appointment programs, and Patrick Hanaway, MD for his support with program development. The authors would also like to thank Sarah Thomsen-Ferreira (Manager of Clinical Nutrition, Center for Functional Medicine) for reviewing this manuscript and her assistance with describing the nutritional intervention. The authors would also like to thank Brittany Lapin, PhD and Amy Nowacki, PhD (Biostatisticians, Quantitative Health Sciences at Cleveland Clinic) for their statistical guidance, and Alex Milinovich, BA (Director of Research Data Science Analytics, Quantitative Health Sciences at Cleveland Clinic) for his assistance with collecting data.

Contributors All authors designed the project. MB drafted the manuscript. NG performed the statistical analyses. All authors reviewed and edited the manuscript. All authors approved the final manuscript.

Funding The authors have not declared a specific grant for this research from any funding agency in the public, commercial or not-for-profit sectors.

Competing interests MB, PhD reports personal fees from Cleveland HeartLab, Inc. outside the submitted work. In addition, MB has a patent number 20110269150 issued. TJ, MBA reports personal consulting fees from DMH Enterprises outside of work at Cleveland Clinic and MH, MD, receives royalties from publication of books on nutrition and income from the sale of nutritional supplements from Vitamin Portfolio. All other authors have no conflicts of interest to report.

Patient consent for publication Not required.

Ethics approval The study was approved by the Institutional Review Board (IRB) of Cleveland Clinic.
Provenance and peer review Not commissioned; externally peer reviewed.

Data availability statement All data relevant to the study are included in the article or uploaded as supplemental information. Data published within the article are available and will be shared upon reasonable request.

Supplemental material This content has been supplied by the author(s). It has not been vetted by BMJ Publishing Group Limited (BMJ) and may not have been peer-reviewed. Any opinions or recommendations discussed are solely those of the author(s) and are not endorsed by BMJ. BMJ disclaims all liability and responsibility arising from any reliance placed on the content. Where the content includes any translated material, BMJ does not warrant the accuracy and reliability of the translations (including but not limited to local regulations, clinical guidelines, terminology, drug names and drug dosages), and is not responsible for any error and/or omissions arising from translation and adaptation or otherwise.

Open access This is an open access article distributed in accordance with the Creative Commons Attribution Non Commercial (CC BY-NC 4.0) license, which permits others to distribute, remix, adapt, build upon this work non-commercially, and license their derivative works on different terms, provided the original work is properly cited, appropriate credit is given, any changes made indicated, and the use is non-commercial. See: http://creativecommons.org/licenses/by-nc/4.0/.

ORCID iD

Michelle Beidelschies http://orcid.org/0000-0002-6344-0674

\section{REFERENCES}

1 Buttorff C, Ruder T, Bauman M. Multiple chronic conditions in the United States, 2017.

2 National Center for Chronic Disease Prevention and Health Promotion. Health and economic costs of chronic disease. Available: https://www.cdc.gov/chronicdisease/about/costs/index.htm\#ref1 [Accessed 20 Aug 2020].

3 Shanafelt TD, West CP, Sinsky C, et al. Changes in burnout and satisfaction with work-life integration in physicians and the general us working population between 2011 and 2017. Mayo Clin Proc 2019;94:1681-94.

4 Association of American Medical Colleges. The complexities of physician supply and demand: projections from 2018-2033, 2020.

5 Cresci G, Beidelschies M, Tebo J, et al. Educating future physicians in nutritional science and practice: the time is now. J Am Coll Nutr 2019;38:387-94.

6 Noffsinger E. Will drop-in group medical appointments (DIGMAs) work in practice? Permanente J 1999;3:58-67.

7 Menon K, Mousa A, de Courten MP, et al. Shared medical appointments may be effective for improving clinical and behavioral outcomes in type 2 diabetes: a narrative review. Front Endocrinol 2017:8:263.

8 Hartzler ML, Shenk M, Williams J, et al. Impact of collaborative shared medical appointments on diabetes outcomes in a family medicine clinic. Diabetes Educ 2018;44:361-72.

9 Noya C, Alkon A, Castillo E, et al. Shared medical appointments: an academic-community partnership to improve care among adults with type 2 diabetes in California central Valley region. Diabetes Educ 2020;46:197-205.

10 Egger G, Stevens J, Volker N, et al. Programmed shared medical appointments for weight management in primary care: an exploratory study in translational research. Aust J Gen Pract 2019;48:681-8.

11 Shibuya K, Ji X, Pfoh ER, et al. Association between shared medical appointments and weight loss outcomes and anti-obesity medication use in patients with obesity. Obes Sci Pract 2020;6:247-54.

12 Bartley KB, Haney R. Shared medical appointments: improving access, outcomes, and satisfaction for patients with chronic cardiac diseases. J Cardiovasc Nurs 2010;25:13-19.

13 Law T, Jones S, Vardaman S. Implementation of a shared medical appointment as a holistic approach to CHF management. Holist Nurs Pract 2019;33:354-9.

14 Lin A, Cavendish J, Boren D, et al. A pilot study: reports of benefits from a 6-month, multidisciplinary, shared medical appointment approach for heart failure patients. Mil Med 2008;173:1210-3.

15 Parikh M, Rajendran I, D'Amico S, et al. Characteristics and components of medical group visits for chronic health conditions: a systematic scoping review. J Altern Complement Med 2019;25:683-98.

16 Romanelli RJ, Dolginsky M, Byakina Y, et al. A shared medical appointment on the benefits and risks of opioids is associated with improved patient confidence in managing chronic pain. $J$ Patient Exp 2017;4:144-51. 
17 Federman DG, Poulin LM, Ruser CB, et al. Implementation of shared medical appointments to offer battlefield acupuncture efficiently to veterans with pain. Acupunct Med 2018;36:124-6.

18 Riley SB. Improving diabetes outcomes by an innovative group visit model: a pilot study. J Am Assoc Nurse Pract 2013;25:466-72.

19 Seesing FM, Groenewoud HJ, Drost G, et al. Cost-effectiveness of shared medical appointments for neuromuscular patients. Neurology 2015;85:619-25.

20 Smith SP, Elias BL. Shared medical appointments: balancing efficiency with patient satisfaction and outcomes. Am J Manag Care 2016;22:491-4.

21 Kirsh SR, Aron DC, Johnson KD, et al. A realist review of shared medical appointments: how, for whom, and under what circumstances do they work? BMC Health Serv Res 2017;17:113

22 Edelman D, McDuffie JR, Oddone E. VA evidence-based synthesis program reports. In: Shared medical appointments for chronic medical conditions: a systematic review. Washington, DC: Department of Veterans Affairs (US), 2012.

23 Stults CD, McCuistion MH, Frosch DL, et al. Shared medical appointments: a promising innovation to improve patient engagement and ease the primary care provider shortage. Popul Health Manag 2016;19:11-16.

24 Trickett KH, Matiaco PM, Jones K, et al. Effectiveness of shared medical appointments targeting the triple aim among patients with overweight, obesity, or diabetes. J Am Osteopath Assoc 2016;116:780-7.

25 The Institute for Functional Medicine. Functional medicine determines how and why illness occurs and restores health by addressing the root causes of disease for each individual. Available: https://www.ifm.org/functional-medicine/ [Accessed 10 Apr 2020].

26 Beidelschies M, Alejandro-Rodriguez M, Ji X, et al. Association of the functional medicine model of care with patient-reported healthrelated quality-of-life outcomes. JAMA Netw Open 2019;2:e1914017.

27 Cleveland Clinic Center for Functional Medicine. Functioning for life. Available: https://my.clevelandclinic.org/departments/functionalmedicine/programs/functioning-for-life-appointments [Accessed 20 Aug 2020].

28 Noffsinger E. Running group visits in your practice. 1st edn. New York: Springer-Verlag, 2009.

29 The Institute for Functional Medicine. ReNew food plan stabilizes blood sugar, insulin. Available: https://www.ifm.org/news-insights/ toolkit-renew-food-plan-stabilizes-blood-sugar-insulin/ [Accessed 20 Aug 2020].

30 von Elm E, Altman DG, Egger M, et al. The strengthening the reporting of observational studies in epidemiology (STROBE) statement: guidelines for reporting observational studies. Int J Surg 2014;12:1495-9.

31 Katzan I, Speck M, Dopler C, et al. The knowledge program: an innovative, comprehensive electronic data capture system and warehouse. AMIA Annu Symp Proc 2011;2011:683-92.

32 Cella D, Riley W, Stone A, et al. The patient-reported outcomes measurement information system (PROMIS) developed and tested its first wave of adult self-reported health outcome item banks: 2005 2008. J Clin Epidemiol 2010;63:1179-94.

33 Yost KJ, Eton DT, Garcia SF, et al. Minimally important differences were estimated for six patient-reported outcomes measurement information System-Cancer scales in advanced-stage cancer patients. J Clin Epidemiol 2011;64:507-16.

34 Norman GR, Sloan JA, Wyrwich KW. Interpretation of changes in health-related quality of life: the remarkable universality of half a standard deviation. Med Care 2003;41:582-92.

35 Austin PC. Balance diagnostics for comparing the distribution of baseline covariates between treatment groups in propensity-score matched samples. Stat Med 2009;28:3083-107.

36 Wadsworth KH, Archibald TG, Payne AE. Shared medical appointments and patient-centered experience: a mixed-methods systematic review. BMC Fam Pract 2019;20:97.

37 Schneeberger D, Golubíc M, Moore HCF, et al. Lifestyle MedicineFocused shared medical appointments to improve risk factors for chronic diseases and quality of life in breast cancer survivors. $J$ Altern Complement Med 2019;25:40-7.

38 Cole RE, Boyer KM, Spanbauer SM, et al. Effectiveness of prediabetes nutrition shared medical appointments: prevention of diabetes. Diabetes Educ 2013;39:344-53.

39 Taveira TH, Dooley AG, Cohen LB, et al. Pharmacist-led group medical appointments for the management of type 2 diabetes with comorbid depression in older adults. Ann Pharmacother 2011;45:1346-55.

40 Watts SA, Gee J, O'Day ME, et al. Nurse practitioner-led multidisciplinary teams to improve chronic illness care: the unique strengths of nurse practitioners applied to shared medical appointments/group visits. J Am Acad Nurse Pract 2009;21:167-72.

41 Davis S, Johnson V, McClory M, et al. Diabetes empowerment with a nurse-led shared medical appointment program. Nursing 2019;49:67-9.

42 Blumenthal KJ, Chang Y, Ferris TG, et al. Using a self-reported globa health measure to identify patients at high risk for future healthcare utilization. J Gen Intern Med 2017;32:877-82.

43 Desroches S, Lapointe A, Ratté S. Interventions to enhance adherence to dietary advice for preventing and managing chronic diseases in adults. Cochrane Database Syst Rev 2013;2:CD008722.

44 Bailey SC, Brega AG, Crutchfield TM, et al. Update on health literacy and diabetes. Diabetes Educ 2014;40:581-604.

45 Smith SG, O'Conor R, Curtis LM, et al. Low health literacy predicts decline in physical function among older adults: findings from the LitCog cohort study. J Epidemiol Community Health 2015;69:474-80.

46 Uemura K, Yamada M, Okamoto H. Effects of active learning on health literacy and behavior in older adults: a randomized controlled trial. J Am Geriatr Soc 2018;66:1721-9.

47 Uemura K, Kamitani T, Yamada M, et al. Longitudinal effects of active learning education on lifestyle behavior and physical function in older adults. J Am Med Dir Assoc 2021;22:459-63. 